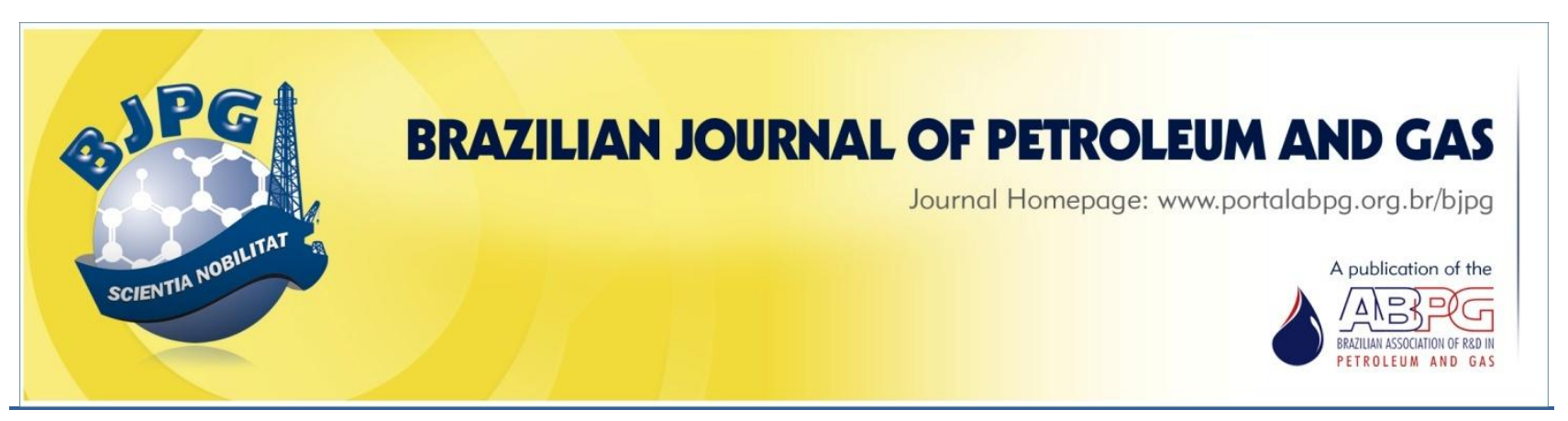

\title{
PRESSURE DROP MODELS FOR PARAFFINIC OIL FLOW
}

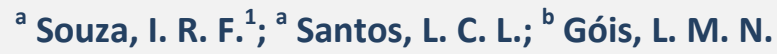 \\ ${ }^{\text {a }}$ Federal University of Bahia (UFBA), Graduate Program of Chemical Engineering, Salvador - BA - Brazil \\ ${ }^{b}$ UNIFACS, Graduate Program of Chemical Engineering, Salvador - BA - Brazil
}

Received: 14.06.2018 / Revised: 06.08.2018 / Accepted: 28.08.2018 / Published on line: 17.10.2018

\begin{abstract}
Wax deposition is a common phenomenon that occurs when crude oil flows in a pipeline. It is one of the main problems related to flow maintenance, because it leads to flux limitation and pressure drop increase. In addition, it can produce major damage to equipment, creating high-risk in operation or even a complete shutdown of production, impacting profitability negatively. Thus, this research aims to show pressure drop models based on Darcy-Weisbach and Power Fluid model for single-phase flow of paraffinic oils in horizontal lines. It will investigate aspects such as different flows, outdoor temperatures, and the BSW (Basic Sediments and Water) values observing their influence on flow pressure. Experimental data from paraffinic oil wells were used to validate the models. The results showed good fit of the models to the data of the eight experiments, with high values of adequacy coefficient $\left(R^{2}\right)$ above 0.97 . Experiments with higher BSW content and lower ambient temperature had a greater impact on the pressure drop, being well represented by the two models.
\end{abstract}

\section{KEYWORDS}

paraffinic oils; pressure drop; single-phase flow; non-Newtonian fluid; Newtonian fluid

\footnotetext{
${ }^{1}$ To whom all correspondence should be addressed.

Address: Federal University of Bahia, Graduate Program of Chemical Engineering, R. Prof. Aristides Novis, $02 / 2^{\circ}$ Andar, Federação, Salvador - BA, Brazil.

ZIP Code: 40210-630 | e-mail: Imario@ufba.br

doi:10.5419/bjpg2018-0014
} 


\section{INTRODUCTION}

Petroleum is a mixture of hydrocarbons and contaminants, which often has water associated with its production. Hydrocarbons form a mixture of saturated constituents (paraffins, iso-paraffins, and naphthenes), aromatics, resins, and asphaltenes. In the beginning of the production stage, the arrival of hydrocarbons to the surface depends on factors associated to flow maintenance. The goal is to improve flow rates and increase oil recovery (Ferreiar \& Cardoso, 2011).

The paraffin molecules are dissolved in the oil reservoir, where the temperature ranges from 70 to $150^{\circ} \mathrm{C}$ and the pressure is above 2000 psi. When the oil begins to flow due to thermal exchange, it can reach the wax appearance temperature (WAT), and begin the process of wax precipitation and deposition in the pipe wall (Aum et al., 2016; Chala et al., 2018). The paraffin deposition process itself is considered to be thermodynamically reversible, since if the temperature increases beyond the WAT, the paraffin molecules will be dissolved back into the oil (Bimuratkyzy \& Sagindykov, 2016).

This is one of the main problems related to flow maintenance, especially for offshore production, because it limits the oil flow, leading to pressure drop by friction; increases the energy consumption; causes equipment malfunction; and reduces the effective internal diameter of pipe (Aum et al., 2016).

The precipitation of paraffins and other solids in the pipelines results in less profitability in the order of thousands of dollars per year. It also reduces primary oil treatment efficiency and creates concerns in the area of environmental safety. Therefore, it is important to study the phenomenon of paraffin deposition to operate oil flow systems in a safe and economical way (Xie \& Xing, 2017).

Studies such as the ones conducted by Azevedo and Teixeira (2003) and Aiyejina et al. (2011) report reviews on wax formation in oil flow pipes. The modeling of the wax deposition requires an understanding of the main mechanisms responsible for the transportation of wax molecules from the bulk oil into the tube walls. When oil is flowing under a laminar regime, the transverse transport of the wax to the wall will be determined by the velocity, temperature, and concentration profiles established by the flow.

After reaching WAT, the oil is replaced by nonNewtonian fluid characteristics, that is, the viscosity varies with shear rate. Farah et al. (2005) studied water-in-oil (W/O) emulsions at shear rates between $10 \mathrm{~s}^{-1}$ and $80 \mathrm{~s}^{-1}$ and found that at temperatures below the WAT all samples presented non-Newtonian fluid characteristics, more specifically, as Bingham's fluid, whereas Oliveira et al. (2010) observed that the W/O emulsions had characteristics of a Power fluid. Due to the complexity involved in the analysis of the flow of non-Newtonian fluids, many paraffin oil models consider it as Newtonian fluids, even at temperatures below the WAT.

It is used to study the pressure drop in incompressible and Newtonian steady state flow from Hagen-Poiseuille and Darcy-Weisbach models. Oil flows are more complex and require models that fit their peculiarities, especially when it comes to paraffin oils flow. Researchers, such as Burger et al. (1981), Creek et al. (1999), Huang et al. (2011), and Wang et al. (2015) have studied paraffin deposition mechanisms in pipelines, but there are only a few studies about pressure drop in this kind of flow.

Ribeiro et al. (1997) developed a model for predicting the pressure drop from the previous calculation of the deposit thickness, showing good results despite the lack of optimum accuracy to the experimental data of pressure drop. Bordalo and Oliveira (2007) studied the paraffinic oil flow in single-phase and biphasic water-oil regimes, noticing that in the single-phase regime the pressure drop was continuously greater than in the biphasic one.

Alcântara (2015) developed a pressure drop model in paraffin oil flows based on the Poiseuille Law, adding plots that describe the paraffins deposition from the knowledge of the thermal insulation effect, which occurs due to the increase of the deposit layer formed. Thus, the model was destined to the laminar flow, since the Poiseuille Law is limited to the study of the pressure drop in permanent Newtonian and laminar flows. A way to extend the possibilities of the study would be to use the Darcy-Weisbach equation, which is intended for both laminar and turbulent flows.

Porto and Lima (2017) studied the transient 
flow of paraffinic oil in a two-dimensional system based on the study of Ribeiro et al. (1997), also observing the thermal insulation effect of the deposited paraffin layer from the temperature difference between the external environment and the internal fluid. The authors verified that the dimensionless solubility parameter developed by them was relevant in the determination of the pressure drop, because the greater the dimensionless solubility is the greater the deposit thickness will be, which increases the pressure drop in the flow.

Thus, the main goal of this study was to develop models considering Newtonian and non-Newtonian fluids to evaluate the pressure drop from the Alcântara (2015) model, modifying the basic equation (Poiseuille Law) for the Darcy-Weisbach equation and for the Power Fluid model, while maintaining the other plots developed by the author. The models presented in this study are not based on individual parameters, such as pressure and BSW, but are shown as simplified and alternative models to those already existent. So that, the physical phenomena involved, such as precipitation, deposition observed by deposit growth and the drag of paraffins, are observed.

\section{MATERIALS AND METHODS}

The Tarantino (2013) experimental data were used in this study. The experiments were carried out with water/oil emulsion flowing with different flow rates (Q), water contents (BSW- Basic Sediment and Water), and at different temperatures $(\mathrm{T})$ (Table 1 ).

\subsection{Description models}

\subsubsection{Model 1}

From the observation of the pressure drop behavior and the output temperature of the experiments, Alcântara (2015) noticed the existence of a behavioral change of the pressure drop when the output temperature of the fluid tends to be constant. Thus, he developed a twoperiod model capable of characterizing the behavior of the pressure drop up to the transition temperature $(\mathrm{Tt})$ point and after that point, when the outlet temperature tends to remain constant.

The Darcy-Weisbach equation, as well as the Poiseuille Law, is not adequate to analyze the pressure drop of paraffinic oil flow because it cannot predict the paraffin deposition on the pipe wall. However, it can predict the pressure variation of most of the flows. Thus, the model is based on the Darcy-Weisbach equation, using a constant $C$ as a form of adjustment to the experimental data, and considering constant flow developed, incompressible fluid and steady-state flow with no variation of dimension (Equation 1).

$$
\Delta p=C f \frac{l \rho v^{2}}{2 D}
$$

Where $f$ is the friction factor, $\rho$ the specific mass, $v$ the flow velocity, $\mathrm{D}$ the pipe inner diameter, and $C$ is the setpoint constant.

For laminar flow, the Darcy friction factor is a function of the Reynolds number and the relative roughness of the pipe. When the flow is in laminar regime, the friction factor is given by the following Equation 2:

$$
f=\frac{64}{\operatorname{Re}}
$$

For turbulent flow, the friction factor can be given by the Colebrooke-White equation (Equation $3)$, which is a function of roughness $(\varepsilon)$ and the pipe diameter $(D)$ :

$$
\frac{1}{\sqrt{f}}=-2 \log \left(\frac{\varepsilon}{3.7 D}+\frac{2.51}{R e \sqrt{f}}\right)
$$

Table 1. Variables of the experiments.

\begin{tabular}{lcccccccc}
\hline \multicolumn{1}{c}{ Experiment } & EXP 1 & EXP 2 & EXP 3 & EXP 4 & EXP 5 & EXP 6 & EXP 7 & EXP 8 \\
\hline BSW (\%) & 5 & 5 & 5 & 5 & 35 & 35 & 35 & 35 \\
Flow (mL/min) & 150 & 150 & 200 & 200 & 150 & 150 & 200 & 200 \\
Bath Temp. $\left({ }^{\circ} \mathrm{C}\right)$ & 20 & 25 & 20 & 25 & 20 & 25 & 20 & 25 \\
\hline
\end{tabular}

Source: Tarantino (2013) 
Alcântara (2015) estimated the effect of paraffin deposition based on the thermal insulation effect caused by precipitation and deposition of these compounds. The long chain paraffins deposit at first, and the precipitate is composed of low thermal conductors present in the oil, since the higher the number of carbons is, the higher the specific heat of the compound will be, and, thus, the lower thermal conductivity.

Any increase in temperature of the fluid during the experiment is considered to be a result of the formation of the paraffins insulation layer on the inner wall of the tubing. It reduces the loss of heat from the fluid to the environment, contributing to the increase in the temperature of the fluid. The formation of the precipitate layer leads to increased pressure drop mainly due to the progressive reduction of the effective internal diameter of the pipe and the increased roughness of the walls of the system. Therefore, the model developed quantifies the loss of load caused by the precipitation of paraffins through the thermal insulation effect that it causes.

When replacing the basic equation of the Alcântara (2015) model modified by DarcyWeisbach equation, it is developed Model $\mathbf{1}$, given by Equation 4 that was used in this study:

$$
\begin{aligned}
& \Delta P=C f \frac{l \rho v^{2}}{2 D}+B \sum_{t=200}^{t=t_{t}} \exp [A f(T)]+ \\
& +E \sum_{t=t_{t}}^{t_{i}}\left[f(T)_{i}^{\prime}-f(T)^{\prime \prime}{ }_{i}\right]
\end{aligned}
$$

The term $f(T)$ (Equation 5) was used as a predictor of the phenomenon of the paraffin precipitation in the pressure drop.

$$
f(T)_{i}=\frac{1}{T_{\text {out } \min }}-\frac{1}{T_{\text {out }, i}}
$$

Where $T_{\text {out }, i}$ is the temperature of the oil at the exit of the experimental unit, and the term $T_{\text {out, min }}$ is the lowest exit temperature observed throughout the experiment.

Paraffin precipitation on the inner wall of the tubing occurs steadily during flow. Therefore, the amount of paraffin at a given time (ti) must be a function of the sum of all precipitated paraffin, from the beginning of the flow to the time $t i$.
There is a less pronounced increase in the pressure drop associated with the constant temperature behavior. The constant behavior of the temperature can be explained from the hypothesis that there is a balance between the deposit and the paraffin drag, making the precipitate layer thickness almost constant. Thus, the increase in the pressure drop cannot be explained only by the reduction of the available area for the flow, but also by the increase in the fluid viscosity, caused by the increase of solid paraffins in its medium.

To characterize the behavior of this second period of experiments, the second period was developed with the factors $(T)^{\prime}$ e $(T)^{\prime \prime}$. The factor $f(T)^{\prime}$ was estimated by the difference between the average temperature of the fluid ( $\left.T_{\text {average }}\right)$ and wax appearance temperature (WAT), as one can observe in Equation 6. This term was developed to quantify the impact of paraffin precipitation on pressure drop. It is known that the lower the temperature is, the more paraffins deposit will be, so this factor should increase the lower the fluid temperature is.

$f(T)_{i}^{\prime}=\frac{1}{T_{\text {average }}-W A T}$

The entrainment of the particles deposited on the pipe wall occurs throughout the experiment. The greater the amount of paraffin deposited on the inner walls the smaller the effective internal diameter. This diameter reduction causes an increase in the fluid velocity, since its flow is constant during all the experiments. Thus, the greater the drag force exerted by the fluid in the particles.

The term used to study the paraffin drag during flow was developed as Equation 7:

$f(T)_{i}^{\prime \prime}=\frac{V_{\text {wax entrained }}}{C_{t}}$

Where $C_{t}$ is an adjustment constant and $V_{\text {wax entrained }}$ is the volume of wax entrained during flow (Equation 8).

$V_{\text {wax entrained }}=\frac{C^{\prime} Q^{2}}{\left(R^{2}-\frac{V_{\text {paraffin }}}{\pi l}\right)}$

Where $C^{\prime}$ and $C_{\mathrm{t}}$ are adjustment constants, $R$ is the effective internal radius of the pipe, $l$ is the length 
of the pipe, and $Q$ is the flow rate.

The paraffin volume was considered directly proportional to the factor $(T)^{\prime}$ due to the lack of parameters and the high complexity involved, applying Equation 9 for this study:

$$
V_{\text {paraffin }}=\sum_{t=t_{t}}^{t_{i}} f(T)^{\prime} \cdot C_{t}
$$

\subsubsection{Model 2}

Considering non-Newtonian fluid, the Power Model for steady-state, laminar and incompressible flow in circular tube was used to calculate the pressure drop as the base equation (Equation 10):

$$
\Delta P=\frac{2 m L}{R}\left[\frac{Q\left(\frac{1}{n}+3\right)}{R^{3} \pi}\right]^{n}
$$

The $m$ and $n$ parameters characterize the fluid and refer to the consistency index and flow behavior, respectively. Due to the difficulty of finding values of $m$ and $n$ for paraffinic oils in this study flow conditions, the parameters used were $0.67 \%$ carboxymethylcellulose (CMC) in water, that is, $\mathrm{m}=3.04 .10^{-6}$ bar. $\mathrm{s}^{\mathrm{n}}$ and $\mathrm{n}=0.716$. These values are compatible with the data for water-in-oil paraffinic emulsions presented in Oliveira et al. (2010) under other flow conditions.

Thus, Model 2 maintains the factors that evaluate the precipitation, deposition and drag of paraffins, changing only the base equation for the Power Model adjusted to the experimental data by the constant $\mathrm{C}$, being given by the Equation 11 :

$$
\Delta P=C \frac{2 m L}{R}\left[\frac{Q\left(\frac{1}{n}+3\right)}{R^{3} \pi}\right]^{n}+
$$

$$
+B \sum_{t=200}^{t=t_{t}} \exp [A f(T)]+E \sum_{t=t_{t}}^{t_{i}}\left[f(T)_{i}^{\prime}-f(T)^{\prime \prime}{ }_{i}\right]
$$

Models 1 and 2 were simulated in Microsoft Excel, ${ }^{\circ}$, using the Solver tool to determine the parameters $\mathrm{A}, \mathrm{B}, \mathrm{C}, \mathrm{E}, \mathrm{Ct}$, and $\mathrm{C}^{\prime}$ required to fit the models to the experimental data. As the input temperature control in the experiment was done manually, the authors noticed the occurrence of oscillations in this variable. To minimize the operational errors, the polynomial regression of the input and output temperature data was performed from an Excel function.

\section{RESULTS AND DISCUSSIONS}

Due to the safety conditions, the experiments were finalized when they reached the pressure difference of 8 bar or 6 hours run time. The start data of the flows, up to 200 s, were excluded due to the initial stabilization period of the experimental unit.

In all experiments, initially, the growth of the outlet temperature is accompanied by an exponential growth of the pressure drop. This change is justified by the fact that, at the beginning of the flow, the paraffins deposit quickly forming an insulating layer that hinders the thermal exchange to the external environment, raising the oil temperature (Porto \& Lima, 2017).

The increase in oil temperature causes the increase in paraffin deposition due to the increase of the thermal gradient and, consequently, the concentration gradient which is considered as the driving force for the displacement of the paraffins (Wang et al., 2015). Thus, one can justify the exponential increase in pressure drop in the early stages of the flow.

In experiments 2, 3 and 4, the outlet temperature remains approximately constant, leading to a more linear behavior of the pressure drop. In Experiment 1, the second behavior is not visualized because it quickly reached the safety pressure of the equipment.

The results of pressure drop with Models 1 and 2 of the experiments with BSW of $5 \%$ can be visualized in Figures 1 to 4 :

When comparing the experiments with BSW of $5 \%$, one can observe that at time $t=2200 \mathrm{~s}$, experiment 1 reached the maximum allowed pressure, while the other experiments showed values of pressure drop below 5 bar. According to Wang et al. (2015) and Quan et al. (2015), the higher the pipe wall temperature is the lower is the paraffin deposition by reducing the temperature gradient will be, which is considered to be the 


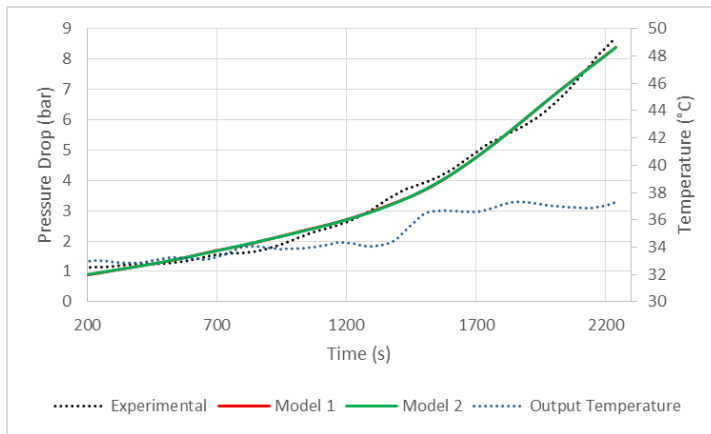

Figure 1. Application of the Model 1 and 2 to the EXP 1.

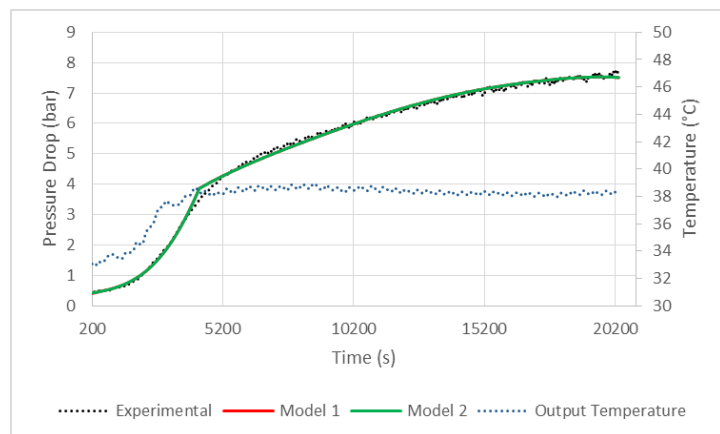

Figure 2. Application of the Model 1 and 2 to the EXP 2.

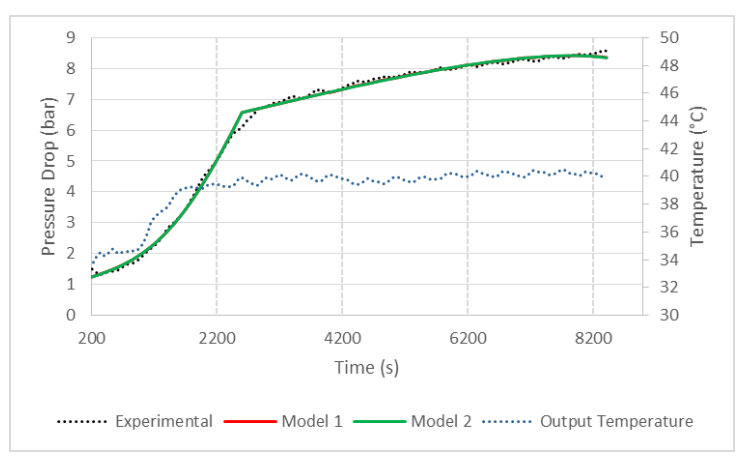

Figure 3. Application of the Model 1 and 2 to the EXP 3.

major driving force in the displacement of the paraffins to the pipe wall. Thus, by reducing the deposition process, the pressure drop is reduced.

Studies by Valinejad and Nasar (2013) and Wang et al. (2015) verify that the increase of the flow rate contributes to the reduction of paraffin deposition by increasing the paraffin drag of the deposit, decreasing its thickness. Thus, the pressure drop becomes less affected by the increase in the flow rate.

Experiments 2 and 4 present higher wall temperature $\left(25^{\circ} \mathrm{C}\right)$ for the present time $\mathrm{t}=2200 \mathrm{~s}$, pressure drop values of $0.71 \mathrm{bar}$ and $1.09 \mathrm{bar}$,

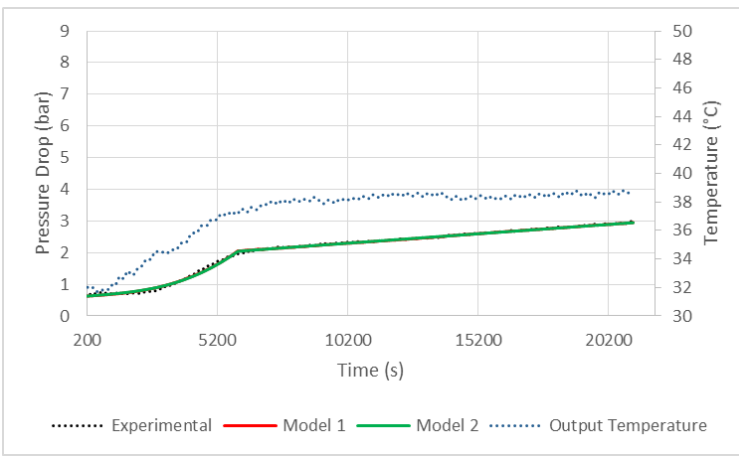

Figure 4. Application of the Model 1 and 2 to the EXP 4.

respectively. Differently, experiments 1 and 3 show a lower bath temperature $\left(20^{\circ} \mathrm{C}\right)$, and pressure drop of 8.37 bar and 5.02 bar, respectively.

For the studied flow rate ranges, one cannot say that it is a dominant variable for the determination of the pressure drop, since the experiment 1 , with a lower flow rate of $150 \mathrm{ml} / \mathrm{min}$, presented the greatest pressure drop among the 4 experiments presented above. Nevertheless, in agreement with Wang et al. (2015), the wall temperature was a determinant variable, since experiments 2 and 4 showed lower values of pressure drop.

The experiments from 1 to 4 , obtained lower pressure drop at the beginning of the flow compared to the last four experiments with higher BSW (35\%), as one can see in Figures 5 to 8.

In agreement with Oliveira et al. (2009), experiments 5 to 8 , with higher BSW, presented higher initial pressure drop, possibly because the presence of water/oil emulsions with higher water content increases the fluid viscosity, thus, increasing the pressure drop by friction loss. With the exception of experiment 1 , all experiments with higher BSW reached the safety pressure faster than the previous ones.

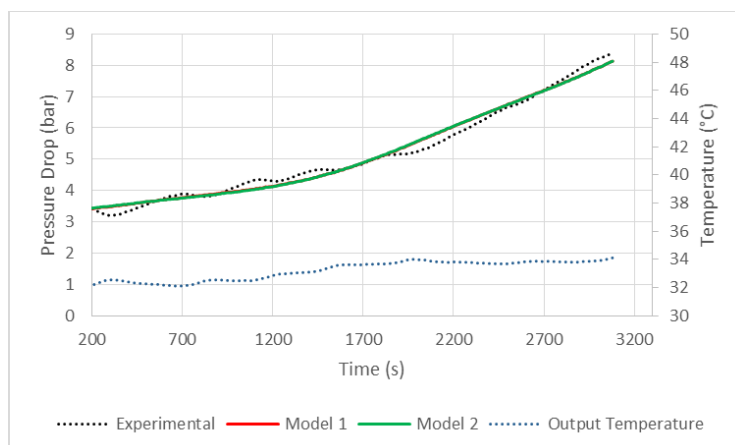

Figure 5. Application of the Model 1 and 2 to the EXP 5. 


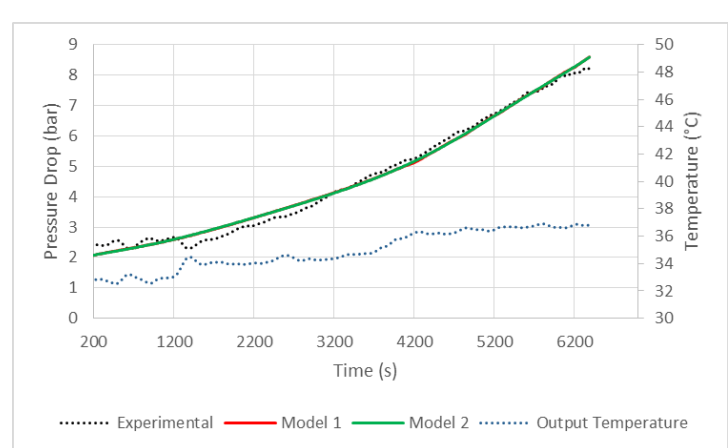

Figure 6. Application of the Model 1 and 2 to the EXP 6.

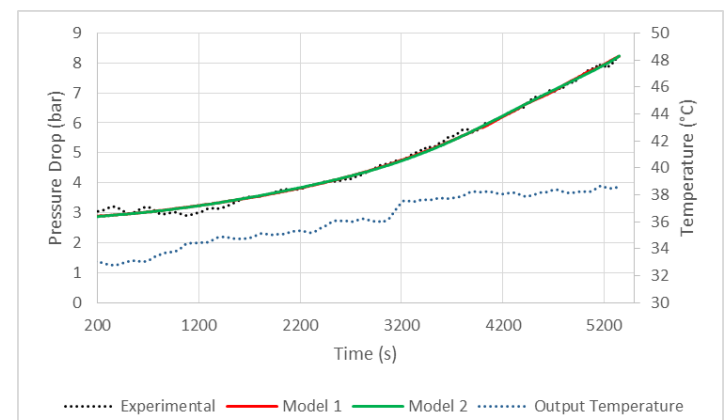

Figure 7. Application of the Model 1 and 2 to the EXP 7.

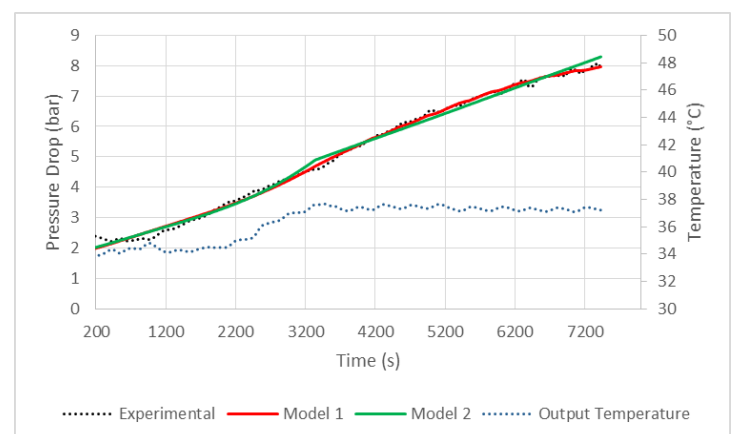

Figure 8. Application of the Model 1 and 2 to the EXP 8.

In Table 2, one can see a comparison between coefficients of determination of models 1 and 2, and the Alcântara (2015) one.

Figures 1 to 8 and Table 2 show a good adjustment of Models 1 and 2 in the experimental data. Similar to the Alcântara model (Alcântara, 2015), it was difficult for the models studied to represent the beginning of the pressure drop behavior of the experiments with BSW of $35 \%$, possibly due to the fact that the pressure drop did not change significantly in the initial moments.

Model 1 showed appropriate values for coefficients of determination, showing good suitability of the use of Darcy-Weisbach modified equation by constant C. Although this study used only laminar flows data, this model can be applied to turbulent flow by using specific friction factor, thus, increasing the possibilities of application when compared to the Alcântara (2015) model.

Model 2 presented a linear behavior for the second period of experiment 8 , resulting in the lowest coefficient of determination (0.972). Zheng et al. (2017) studied the phenomenon of paraffin deposition considering characteristics of Newtonian fluid of the Herschel-Bulkley type, also evaluating the pressure drop. These authors realized that both the Newtonian and nonNewtonian approaches underestimated the pressure drop, but the non-Newtonian approach yielded closer responses to the simulated field data.

The Ribeiro et al. (1997) model for pressure drop did not present coefficient of determination values that could be compared with the results of this study. Despite good results, it failed to accurately predict the experimental data. Porto and Lima (2017) also did not present model validation data that could be compared.

\section{CONCLUSIONS}

Models 1 and 2 presented in this work were effective in demonstrating the pressure drop in paraffinic oils flows, considering the main phenomena of precipitation, deposition, and drag paraffin particles. Comparing with the Alcântara model (Alcântara, 2015), they were able to

Table 2. Coefficients of Determination $\left(R^{2}\right)$.

\begin{tabular}{ccccccccc}
\hline $\mathbf{R}^{2}$ & EXP 1 & EXP 2 & EXP 3 & EXP 4 & EXP 5 & EXP 6 & EXP 7 & EXP 8 \\
\hline Model 1 & 0.993 & 0.992 & 0.988 & 0.988 & 0.985 & 0.990 & 0.995 & 0.985 \\
Model 2 & 0.993 & 0.999 & 0.998 & 0.987 & 0.984 & 0.990 & 0.995 & 0.972 \\
Alcântara (2015) & 0.996 & 0.999 & 0.998 & 0.998 & 0.992 & 0.991 & 0.983 & 0.998 \\
\hline
\end{tabular}


increase their application to turbulent and nonNewtonian flows, respectively. However, the use of specific parameters of paraffinic oils for application of the non-Newtonian model is indicated.

Based on the study, we infer that the models can be applied to field data for evaluation under real conditions, observing the behavior of the pressure drop out of the experimental scale, as well as to improve the models considering the flow of non-Newtonian and turbulent fluid together.

\section{REFERENCES}

Aiyejina, A.; Chakrabarti, D. P.; Pilgrim, A.; Sastry, M. K. S. Wax formation in oil pipelines: A critical review. International Journal of Multiphase Flow, v.37, p.671-694, 2011.

https://doi.org/10.1016/ji.jmultiphaseflow.2011.02.007

Alcântara, M. L. Desenvolvimento de um modelo para a perda de carga em escoamento de óleos parafínicos. 2015. 101 f. Dissertação (Mestrado em Engenharia Química). Universidade Federal da Bahia, Salvador, 2015. (in Portuguese)

Aum, Y. K. P. G.; Aum, P. T. P.; Fonseca, J. L. C.; Barros Neto, E. L.; Dantas Neto, A. A.; Dantas, T. N. C. Analysis of deposition from paraffin-solvent mixtures under turbulent flow. Brazilian Journal of Petroleum and Gas, v.10, n.1, p.009-021, 2016. https://doi.org/10.5419/bjpg2016-0002

Azevedo, L. F. A.; Teixeira, A. M. A critical Review of the Modeling of Wax Deposition Mechanisms. Journal of Petroleum Science and Technology, v. 21, n. 3 and 4, p. 393-408, 2003. https://doi.org/10.1081/LFT-120018528

Bimuratkyzy, K; Sagindykov, B. The rewiew of flow assurance solutions with respect to wax and asphaltene. Brazilian Journal of Petroleum and Gas, v.2, n.10, p.116-134, 2016. https://doi.org/10.5419/bipg2016-0010

Bordalo, S. N.; Oliveira, R. C. Escoamento bifásico óleo-água com precipitação de parafinas em dutos submarinos de produção de petróleo, 2007, Proceedings 4ㅇ PDPETRO, Campinas, SP.
Burger, E. D.; Perkins T. K.; Striegler, J. H. Studies of wax deposition in the Trans Alaska Pipeline. Journal of Petroleum Technology, v. 33, n. 6, p. 1075-1086, 1981.

https://doi.org/10.2118/8788-PA

Chala, G.T.; Sulaiman, S. A.; Japper-Jaafar, A. Flow start-up and transportation of waxy crude oil in pipelines - A rewiew. Journal of Non-Newtonian Fluid, v.251, p.69-87. https://doi.org/10.1016/i.jnnfm.2017.11.008

Creek, J. L.; Lund, H. J.; Brill, J. P.; Volk, M. Wax deposition in single phase flow. Fluid Phase Equilibria, v. 158, p. 801 a 811, 1999.

Farah, M. A.; Oliveira, R. C.; Caldas, J. N.; Rajagopal, K. Viscosity of water-in-oil emulsions: Variations with temperature and water volume fraction. Journal of Petroleum Science and Engineering, v.48, p.169-184, 2005. https://doi.org/10.1016/i.petrol.2005.06.014

Ferreira, C. D. A.; Cardoso, L. F. Estudo da garantia de escoamento em um campo de óleo pesado em lâmina d'água rasa. 2011. 109 f. Monografia (Graduação em Engenharia de Petróleo). Escola Politécnica, Universidade Federal do Rio de Janeiro, Rio de Janeiro, 2011.

Huang, Z.; Lee, H. S.; Senra, M.; Fogler, H. S. A fundamental modelo of wax deposition in subsea oil pipelines. AIChE Journal, v. 57, p. 2955-2964, 2011. https://doi.org/10.1002/aic.12517

Oliveira, M. C. K.; Carvalho, R. M.; Carvalho, A. B.; Couto, B. C.; Faria, F. R. D.; Cardoso, F. L. P. Waxy crude oil emulsion gel: Impact on flow assurance. Energy Fuels, v. 24, p. 2287-2293, 2010. https://doi.org/10.1021/ef900927g

Porto, T. R. N.; Lima, A. G. B. Escoamento transiente de óleo parafínico em duto de seção circular: Modelagem e simulação. Holos, v.1, p. 155-173, 2017. (in Portuguese) https://doi.org/10.15628/holos.2017.5220

Quan, Q.; Gong, J.; Wang, W.; Wang, P. The influence of operating temperatures on wax deposition during cold flow and hot flow of crude oil. Petroleum Science and technology, v.33, p.272-277, 2015. https://doi.org/10.1080/10916466.2014.948120 
Ribeiro, F. S.; Mendes, P. R. S.; Braga, S. L. Obstruction of pipelines due to paraffin deposition during the flow of crude oils. International Journal of Heat and Mass Transfer, v.40, n.18, p. 43194328, 1997. https://doi.org/10.1016/500179310(97)00082-3

Tarantino, G.B. Estudo e avaliação do escoamento de petróleo parafínico. 2013. $75 \mathrm{f}$. Dissertação (Mestrado em Engenharia Química). Universidade Federal da Bahia, Salvador, 2013.

Valinejad, R.; Nazar, A. R. S. An experimental design approach for investigating the effects of operating factors on the wax deposition in pipelines. Fuel, v. 106, p.843-850, 2013. https://doi.org/10.1016/i.fuel.2012.11.080
Wang, W.; Huang, Q.; Wang, C.; Li, S.; Qu, W.; Zhao, J.; He, M. Effect of operating conditions on wax deposition in a laboratory flow loop characterized with DSC technique. Journal of Thermal Analysis and Calorimetry, v.119(1), p.471485, 2015. https://doi.org/10.1007/s10973-014-3976-z

Xie, Y.; Xing, Y. A prediction method for the wax deposition rate based on a radial baiss function neural network. Petroleum, v.3, p.237-241, 2017. https://doi.org/10.1016/i.pet/m.2016.08.003

Zheng, S.; Saidon, M.; Palermo, T.; Mateen, K.; Fogler, H. S. Wax deposition modeling with considerations of non-newtonian characteristcs: Application on field-scale pipeline. Energy Fuels, v.5, p.5011-5023, 2017.

https://doi.org/10.1021/acs.energyfuels.7b00504 